\title{
Humanitarian logistics and emergency relief management: hot perspectives and its optimization approach
}

\author{
Linlin Zhang ${ }^{1}, \mathrm{Na} \mathrm{Cui}^{1 *}$ \\ ${ }^{1}$ School of Civil Engineering and Architecture, University of Jinan, Jinan, Shandong, 250022, China
}

\begin{abstract}
Post-disaster humanitarian relief is full of importance, complexity and difficulty, which makes people pay more attentions to various disaster relief measures and emergency management practices related to disaster preventions and reductions. The main purpose of humanitarian relief is to protect the lives of the victims in the affected areas and provide victims with the indispensable relief materials to survive from the unexpected disaster. Therefore, this paper puts its focus on some key decisions raised in the process of postdisaster humanitarian relief activities and summarizes the state-of-the-art researches in the area of critical emergency facility location, relief material allocation, emergency vehicle routing and the incorporation of the interests of the victims in the modeling framework. Specifically, through the analysis, this paper draws some key questions that can be further explored in the current research, in order to lay the foundation for the follow-up research, and can better serve the emergency rescue transportation practice under disaster conditions.
\end{abstract}

\section{Introduction}

With the frequent occurrence of all kinds of natural disasters (e.g., hurricanes, floods, earthquakes, etc.) and man-made disasters (e.g., terrorism, nuclear power plants, etc.), it has caused huge losses of life and property worldwide. For example, the super typhoon "Haiyan" in 2013 attacked the Philippines, Vietnam, and China at the same time, bringing rainstorms and even torrential rain, and resulted in large-scale traffic and power interruption. The total number of casualties was about 36,185 and the economic losses amounted to 3.69 billion dollars. The 2010 Yushu earthquake in Qinghai province caused about 2,698 deaths, and nearly 200,000 people were affected. For the disaster problem, the United Nations International Strategy for Disaster Reduction Committee (UNISDR) proposed that disaster is a serious damage to a community or the function of the community, causing general human, material, economic or environmental damage, beyond the ability of the affected city or society to use its own resources ${ }^{[1]}$. Djimesah et al. believed that this is the result of the combined effect of concentrated population and assets in vulnerable areas and environment disruptions ${ }^{[2]}$.

Due to the complexity of disaster event, the lack of information and the unpredictability of rescue demand greatly increase the difficulty of humanitarian relief activities, such as the interruption of communication, uncertainty about the disaster scope, the number of casualties, and the number of urgent needs of rescue items. Additionally, the damages of housing and road network infrastructure lead to the "logistics lifeline" inaccessible, resulting in that the rescue personnel and materials are unable to be delivered in time. During this period, the phenomenon of limited available materials and huge consumption keeps occurring. The occurrence of these phenomena may aggravate the sufferings of the victims in the disaster area, so it is significant to quickly carry out external rescue in the shortest time to coordinate the whole relief process, reduce the loss of life and property of the victims, maintain the dignity of the victims, and reduce the sufferings of the victims, i.e., the implementation of humanitarian relief.

\section{Research scope and descriptive analysis}

With the extensive research of commercial logistics and the frequent attack of various disaster events, humanitarian logistics and emergency relief have gradually come into people's sight and become the research focus of researchers at home and abroad in the recent century. Thomas first introduced the concept of humanitarian logistics [3]. He proposed that "humanitarian logistics refers to the process and system of mobilizing human resources, skills and knowledge to help vulnerable groups affected by natural disasters and complex emergencies." At the same time, humanitarian logistics was also considered as "the bridge between disaster prevention and response, material procurement and distribution, headquarters and the field". PerezRodriguez et al. considered that post-disaster humanitarian logistics included "the procurement, transportation and distribution of key materials needed 
by survivors, as well as their own response"[4]. Although it was the most expensive part of the rescue work ${ }^{[3]}$, a comprehensive and effective logistics system was beneficial to the victims, such as reducing the time for individuals to wait for rescue ${ }^{[5]}$. OCHA announced that the lack of logistics and transportation was the most critical problem in the aid effort after the 2010 earthquake, and cooperation was crucial. Besiou et al. believed that the operation of humanitarian logistics was affected by many factors, such as time pressure, lack of resources and uncertainty, and system dynamic model (SD) was an effective method to solve the complexity of humanitarian logistics ${ }^{[6]}$.

In this paper, a series of key issues involved in the humanitarian logistics and emergency relief activities will be reviewed, and the breakthrough point will be put on the optimization modeling efforts, and the following contents will be covered: (1) facility location and relief material allocation; (2) facility location and vehicle routing optimization; (3) the incorporation of the interests of victims (e.g., the deprivation cost in the modeling framework).

\subsection{Facility location and relief material allocation}

There are a lot of research results that considered the locations of the rescue centers and the allocation and transportation of emergency materials in humanitarian logistics. For example, Chang et al. described the uncertain flood emergency logistics problem as two stochastic programming models, aiming to determine the inventory location and the material allocation strategies to the demand points, and to distribute relief materials to the disaster affected areas ${ }^{[7]}$. $\mathrm{Ni}$ et al. considered the proportion of preset inventory that could be used after a disaster, established a min-max robust model to deal with the uncertainty of some key parameters, and optimized facility location, emergency inventory preset and rescue transportation ${ }^{[8]}$. On the premise of considering the risk of service interruptions, An et al. established an evacuation pickup facility location model by considering the pickup and transfer activities occurred in both the pre- and post-disaster phases, and key decisions also included the resource deployment ${ }^{[9]}$. Rawls et al. took into account the uncertainty of inventory supply demand and available transportation network after the disaster, and proposed a two-stage stochastic mixed integer programming model to determine the facility location and the preset quantity of emergency supplies ${ }^{[10]}$. Cotes et al. developed a location model for pre-disaster supply facilities to determine the number of preset items to provide services for the affected areas ${ }^{[11]}$.

$\mathrm{Yu}$ et al. added the importance of time factor in the location of emergency facilities and constructed the location-allocation optimization model of maximum time satisfaction of emergency facilities ${ }^{[12]}$. Li et al. built a multi-objective optimization model for location and allocation of regional emergency material storage by minimizing the sum of setup cost, variable cost, material transportation cost and total material transportation time [13]. Li et al. established a multi-objective location- multimodal transportation optimization model for postdisaster emergency material allocation in earthquake event, with the objective of minimizing the total time of emergency material allocation and the total loss of unsatisfied emergency materials at the disaster area ${ }^{[14]}$. Zheng et al. discussed the disaster relief network system of transporting various kinds of emergency materials from the accumulation point to the distribution center and then to the disaster stricken areas, and established a bi-level programming model ${ }^{[15]}$. Chen et al. presented a multi-objective emergency logistics location-allocation model with multi-commodity, multi-modal transportation, and multi-stage under the situation of uncertain supply and demand of emergency materials ${ }^{[16]}$. With the propose of minimizing the total cost of the system and maximizing the coverage of customer demand, Guo et al. constructed a bi-objective mixed integer programming model which concentrated on the facility reliability and obtained the location of the emergency logistics center and the material allocation decisions ${ }^{[17]}$.

\subsection{Facility location and vehicle routing optimization}

The vehicle scheduling problem of humanitarian relief supplies has gradually become the focus of logistics academia and practitioners. Vehicle routing optimization is closely related to the purpose of reducing human suffering and increasing survival probability, thus combining the location of emergency service facilities with the optimization of vehicle routing is another focus in the field of humanitarian emergency logistics [18-19]. Unlike commercial logistics routes which usually take the shortest distance or the minimum operation cost as the main decision-making objective, the choice of humanitarian rescue routes is mainly to minimize the rescue time, maximize the survival probability, or reduce the loss of life and human sufferings to the greatest extent ${ }^{[20-21]}$. Hajibabai et al. considered the vehicle routing optimization of snow sweeper under the constraint of limited resources, and established a mixed integer linear programming model to minimize the total running time of snow sweeper to complete the snow sweeping route and reduce the maximum time of a single truck [22]. In addition, in the emergency routing optimization of transporting victims, different link/path damage degree and desired survival probability were considered and integrated in the path selection decision. The transportation priority issue was usually a dominant factor in the decision process, especially when there are not enough relief resources to meet all the victims, and mostly the severely injured need to be given higher priority than the lightly injured ${ }^{[23-25]}$. Based on the consideration of the fairness and priority, Zhu et al. established two models to deal with the same and different degrees of link damages and carried out vehicle routing optimization. A meta-heuristic algorithm based on ant colony algorithm was developed to accelerate the convergence speed of the solution ${ }^{[26]}$.

Under the conditions of uncertain environment, the location-routing problem of emergency logistics system 
becomes increasingly hot in the field of humanitarian relief. Zheng et al. used fuzzy programming method to study the location-routing optimization model with fuzzy demand in emergency logistics system [27]. Dai et al. considered the randomness of emergency material demand and rescue vehicle travel time, and established a stochastic location-routing optimization model with time window in emergency logistics system by using stochastic programming method ${ }^{[28]}$. Considering the uncertainty of the rescue environment, Liu proposed a multi-center and multi-material network flow model for the distribution of post-disaster humanitarian relief materials. The model assumed that all vehicles only took the most reliable route and used the triangular whitening weight function grey evaluation method to deal with the uncertainty of the rescue environment and selected the most reliable routing from the distribution center to the disaster site ${ }^{[29]}$

\subsection{The incorporation of the interests of victims}

Compared with commercial logistics research, humanitarian emergency logistics study needs to integrate many human oriented considerations. Deprivation cost is one of the forms to quantify the loss of waiting victims and its's also an effective way to express the social cost occured in the emergency rescue process. The concept of deprivation cost was first proposed by Holguín-Veras et al., and it was the economic value of the human suffering caused by the inability to obtain a good or service. Holguín-Veras et al. assumed that the deprivation cost function should be (1) monotonic, nonlinear and convex with respect to deprivation time; (2) related to non-superimposed demand, and possibly related to the hysteretic effect representing the beneficiaries of residual damage ${ }^{[30]}$. In the following study, Holguín-Veras et al. estimated the deprivation cost function through conditional value experiment. Their method was to reduce the probability of death and how much a person was willing to pay for key goods or services. The results showed that the deprivation cost of drinking water increased nonlinearly with the deprivation time ${ }^{[31]}$. Cantillo et al. used discrete choice theory to evaluate the deprivation cost caused by the delivery of basic goods after the disaster. It showed that the external cost (i.e., deprivation cost) caused by the delayed delivery of basic commodities was nonlinear, strictly increasing, and convex in the deprivation time. Some socio-economic variables, such as age and gender, were added to the model to reveal the difference of deprivation time value and explained the difference of individual preferences ${ }^{[32]}$. Cotes et al. used the consumer surplus formula to calculate the deprivation cost function [11]. Shao et al. analyzed the current situation of deprivation cost and discussed the key issues in the study of deprivation cost from the following aspects: estimation method, application of deprivation cost, estimation differences, challenges and obstacles ${ }^{[33]}$. Zhu et al. considered the relative deprivation cost and absolute deprivation cost, and the deprivation cost function was determined by the exponential growth function obtained by Holguín-Veras et al. ${ }^{[26]}$. PérezRodríguez et al. put the operating cost and deprivation cost into the decision-making process to reduce the total social cost and human sufferings and put forward a formula of limited commodity distribution ${ }^{[4]}$.

\section{Conclusions and future research development}

Based on the analysis of several key issues in the process of humanitarian relief: humanitarian logistics, facility location and relief material allocation, facility location and vehicle routing optimization, victims' personal interests, this paper has a certain understanding of the current research status in this field at home and abroad, summarizes and analyzes the shortcomings of the existing research, and sorting out the following research directions.

Although scholars at home and abroad have carried out a large number of researches, there are still many problems to be solved in this research field. Some key problems that can be further expanded or some shortcomings of existing researches are summarized as follows:

(1) Lack of in-depth research on the characterization of the victims' personal interests. Due to the lack of key relief materials, the quantitative estimation of the victims' suffering is still in the basic research stage, which is not in-depth. Basically, a large number of studies only consider the suffering of the disaster victims separately, and have not been integrated into the modeling framework, which lacks the comprehensive consideration of the rescue center location, the allocation and transportation of materials and the victims' personal interests.

(2) Lack of systematic research on multi-level service network. In the process of humanitarian rescue under disaster conditions, the road conditions and the demand for relief items are full of uncertainty. Most of the previous studies only focused on the secondary service network, and preferred the assumptions of known demand and sufficient material storage in the rescue center. They did not comprehensively consider the multilevel service network rescue operation process, and lacked systematic research on the actual rescue process.

(3) Lack of further research on humanitarian emergency transportation strategy. Although disaster relief routing planning has become a hot topic in the field of humanitarian rescue, facility location and vehicle routing optimization are two-stage mixed integer nonlinear programming problems, it is difficult to design and solve the algorithm, and solve them at the same time. At present, there is a lack of consideration in this aspect in China.

According to the above analysis, we will take the predisaster material storage and post-disaster relief material transportation allocation as the core problem to carry out the research and strive to solve the main problem is to minimize the victims' suffering on the basis of considering the actual network operation process, such as the rescue center facility location, multi-level service 
network design, material transportation allocation and vehicle routing optimization.

\section{Acknowledgments}

This research was supported by the National Natural Science Foundation of China (NSFC) (Grant \# 71874069) and Youth Innovation Support Program of Shandong Colleges and Universities.

\section{References}

1. UNISDR. (2005) Hyogo Framework for Action 2005-2015 Building the Resilience of Nations and Communities to Disasters. World Conference on Disaster Reduction, 01: 1-25.

2. Djimesah, I.E., Okine, A.N.D., Mireku, K.K. (2018) Influential factors in creating warning systems towards flood disaster management in Ghana: An analysis of 2007 Northern flood. International Journal of Disaster Risk Reduction, 28: 318-326.

3. Thomas, A. (2004) Humanitarian Logistics Enabling Disaster Response. San Francisco: Fritz Institute.

4. Pérez-Rodríguez, N., Holguín-Veras, J. (2016) Inventory-Allocation Distribution Models for Postdisaster Humanitarian Logistics with Explicit Consideration of Deprivation Costs. Transportation Science, 50(4): 1261-1285.

5. Thomas, A., Mizushima, M. (2005) Logistics Training Necessity or Luxury. Forced Migration Review, 22: 60-61.

6. Besiou, M., Stapleton, O., Van Wassenhove, L.N., (2011) System dynamics for humanitarian operations. Journal of Humanitarian Logistics and Supply Chain Management, 1(01): 78-103.

7. Chang, M.S., Tseng, Y.L., Chen, J.W. (2007) A scenario planning approach for the flood emergency logistics preparation problem under uncertainty. Transport Research Part E: Logistics and Transportation Review, 43(6): 737-754.

8. Ni, W., Shu, J., Song, M. (2018) Location and Emergency Inventory Pre-Positioning for Disaster Response Operations: Min-Max Robust Model and a Case Study of Yushu Earthquake. Production and Operations Management, 27(1): 160-183.

9. An, S., Cui, N., Li, X., Ouyang, Y. (2013) Location planning for transit-based evacuation under the risk of service disruptions. Transportation Research Part B: Methodological, 54: 1-16.

10. Rawls, C.G., Turnquist M.A. (2010) Prepositioning of emergency supplies for disaster response. Transportation Research Part B: Methodological, 44(4): 521-534.
11. Cotes, N., Cantillo, V. (2019) Including deprivation costs in facility location models for humanitarian relief logistics. Socio-Economic Planning Sciences, 65: 89-100.

12. Yu, D., Gao, L., Zhao, S. (2018) Locationallocation Optimization Model for Emergency Facilities and Algorithm with Maximum Time Satisfaction. Systems Engineering, 36(02): 95-102.

13. Li, Z., Wang, S., Wang, F. (2014) Locationallocation model and algorithm for regional reserve depots of emergency materials. Computer Engineering and Applications, 50(16): 226-231.

14. Li, S., Ma, Z., Zheng, B., Dai, Y. (2013) Fuzzy Multi-Objective Location -Multimodal Transportation Problem for Relief Delivery during the Initial Post-earthquake Period. Chinese Journal of Management Science, 21(02): 144-151.

15. Zheng, B., Ma, Z., Zhou, Y. (2017) Bi-level Model for Dynamic Location -Transportation Problem for Post-earthquake Relief Distribution. Journal of Systems \& Management, 26 (02), 326337.

16. Chen, G., Zhang, J., Fu, J. (2016) A multiobjective location-allocation model for emergency logistics in an uncertain information environment. China Safety Science Journal, 26(12): 163-168.

17. Guo, Y., Hu, D., Zhu, L., Duan, C. (2017) Study on modeling for location- allocation problem of emergency logistics facility considering reliability element. Journal of Safety Science and Technology, 13(02): 85-89.

18. Van Wassenhove, L.N. (2006) Humanitarian aid logistics: Supply chain management in high gear. Journal of Operations Research Society, 47(5): 475-489.

19. Jabbour, C.J.C., Sobreiro, V.A., Jabbour, A.B.L.S., Campos, L.M.S., Mariano, E.B., Renwick, D.W.S. (2017). An analysis of the literature on humanitarian logistics and supply chain management: Paving the way for future studies. Annals of Operations Research, 5/6, 1-19.

20. Balcik, B., Beamon, B.M. (2008) Performance measurement in humanitarian relief chains. International Journal of Public Sector Management, 21(1): 4-25.

21. Sabouhi, F., Bozorgi-Amiri, A., Moshref-Javadi, M., Heydari, M. (2018) An integrated routing and scheduling model for evacuation and commodity distribution in large-scale disaster relief operations: A case study. Annals of Operations Research.

22. Hajibabai, L., Nourbakhsh, S.M., Ouyang, Y., Peng, F. (2013) Snow Plow Routing Optimization under Resource Constraints: Formulation, Algorithm, and Decision-Support System. Transportation Research Board 92nd Annual Meeting. 
23. Özdamar, L., Ertem, M.A. (2015) Models, solutions and enabling technologies in humanitarian logistics. European Journal of Operational Research, 244(1): 55-65.

24. Tofighi, S., Torabi, S.A., Mansouri, S.A. (2016) Humanitarian logistics network design under mixed uncertainty. European Journal of Operational Research, 250(1): 239-250.

25. Saghafian, S., Hopp, W.J., Oyen, M.P.V., Desmond, J.S., Kronick, S.L. (2014) Complexity augmented triage: A tool for improving patient safety and operational efficiency. Manufacturing \& Service Operations Management, 16(3): 329345 .

26. Zhu, L., Gong, Y., Xu, Y., Gu, J. (2018) Emergency relief routing models for injured victims considering equity and priority. Annals of Operations Research.

27. Zheng, B., Ma Z., Fang, T. (2009) Fuzzy Multiobjective Location-routing Problem in Emergency Logistics Systems. Systems Engineering, 27(08): 21-25.

28. Dai, Y., Ma, Z. (2012) Stochastic LocationRouting Problem in Emergency Logistics System. Journal of Systems \& Management, 21 (02): 212217.

29. Liu, Y. (2017) The Humanistic Rescue Resource Allacation under Uncertain tine. Shandong University.

30. Holguín-Veras, J., Perez, N., Jaller, M., Van Wassenhove, L.N., Aros-Vera, F. (2013) On the appropriate objective function for post-disaster humanitarian logistics models. Journal of Operations Management, 31(5): 262-280.

31. Holguín-Veras, J., Amaya-Leal, J., Cantillo, V., Van Wassenhove, L.N., Aros-Vera, F., Jaller, M. (2016) Econometric estimation of deprivation cost functions: A contingent valuation experiment. Journal of Operations Management, 45(1): 44-56.

32. Cantillo, V., Serrano, I., Macea, L.F., HolguínVeras, J. (2018) Discrete choice approach for assessing deprivation cost in humanitarian relief operations. Socio-Economic Planning Sciences, 63: 33-46.

33. Shao, J., Wang, X., Liang, C., Holguín-Veras, J. (2019) Research progress on deprivation costs in humanitarian logistics. International Journal of Disaster Risk Reduction. 